COMMENTARY

\title{
A unifying theoretical framework for clinical psychology
}

\section{Liane Leedom}

University of Bridgeport, Bridgeport, United States

Clinical psychology lacks a theoretical framework through which to interpret and apply research findings. This comment explains the theoretical framework of ethology, a discipline that is extinct in the United States. The ethologists Lorenz and Tinbergen developed behavioral systems theory as a means to place the proximal causes of behaviors within the context of adaptive goals. This comment asserts that there are four adaptive goals that motivate human social behavior: attachment/affiliation, caregiving, dominance and sex. Tinbergen developed the four questions of ethology as a complete explanation for behavior. The articles in this volume are discussed in terms of behavioral systems theory and the four questions of ethology.

KEY WORDS

human personality; behavioral system; personality disorders

CORRESPONDING AUTHOR - Liane Leedom, Ph.D., University of Bridgeport, 206 Park Avenue, 06604 Bridgeport, CT, United States, e-mail: Ileedom@bridgeport.edu

AUthors' CONTRIBUtION - A: Study design - B: Data collection - C: Statistical analysis - D: Data interpretation .

E: Manuscript preparation · F: Literature search · G: Funds collection

TO CITE THIS ARTICLE - Leedom, L. (2018). A unifying theoretical framework for clinical psychology. Current Issues in

Personality Psychology, 6(4), 343-348.

RECEIVED 16.10.2018 · REVIEWED 22.10.2018 · ACCEPTED 22.10.2018 · PUBLISHED 21.11.2018 
$\mathrm{I}^{\mathrm{n}}$ their editorial, Drs. Soroko and Górska (2018) state that there is a "lack of theory in a significant number of studies" in psychology. They also note that, "An important perspective, which we call a 'theory-embedded' stance, is to some extent disregarded in scientific research in clinical psychology". I agree that the failure of psychology to adopt a unifying theory for human behavior has prevented the application of sound research to clinical practice. Lack of a coherent unified theory has also hindered public education regarding mental health and how best to achieve it. In this editorial, I describe one contender for a unifying theory of human behavior and examine the articles in this volume using a "theory-embedded" stance.

Although psychology has no accepted unifying theory, the ground work for such a theory was laid between 1865 and 1943, during the same years quantum mechanics was developed. The social forces of World War II that drove the acceptance of quantum mechanics and its application to the atom bomb led to the demise of the discipline that could have provided the unified theory of human behavior. Prior to World War II, the ethologists Lorenz and Tinbergen founded the discipline of ethology that sought unifying explanations for behavior (Burkhardt, 2005). The two important contributions of these ethologists were: 1) the behavioral systems framework (Bowlby, 1980); and 2) Tinbergen's four questions (Tinbergen, 1963). Following the holocaust, Jewish scholars immigrated to the United States and discovered that Lorenz had been a Nazi. Although he was awarded the Nobel Prize in 1974, his work and ideas were discredited and his discipline abolished by American psychology (Bateson, Bateson, \& Klopfer, 1989; Burkhardt, 2005). Although there were good reasons for the demise of ethology, the baby was thrown out with the proverbial bath water such that many reading this work are likely unfamiliar with the meaning of behavioral systems and Tinbergen's four questions. Nonetheless, the theoret- ical framework of ethology through behavioral systems and the four questions provides a foundation for interpreting the findings of the papers in this volume.

\section{BEHAVIORAL SYSTEMS}

Early ethologists adopted an engineering model for the understanding of behavior; they conceived of behaviors as organized into cybernetic systems (Figure 1) (Hinde, 1982). All cybernetic systems have: 1) a superordinate goal or purpose; 2) a sensor that monitors the environment for goal relevant stimuli; 3) a comparator that evaluates the discrepancy between the perceived state and the desired state; and 4) enactors that work to resolve the discrepancy. Human social behavioral systems have neural circuits that: pursue goals (determined by natural selection); monitor the environment for salient stimuli; compare the desired state to the perceived state of goal attainment; and enact behaviors relevant to the goal. Because cybernetic systems do work, they require energy. The work done by behavioral systems also requires energy. This energy is felt by individuals as drive or motivation. The comparator contains an internal representation (working model) of both the goal and means to acquire the goal; the comparator function is conceived of as "object relations" within psychoanalytic theory. The importance of behavioral systems was recognized by Bowlby (1988), who wrote extensively about the "attachment system;" and was magnified by Gray (1990), who conceptualized the "behavioral inhibition system" and the "behavioral activation system." More recently, Carver and colleagues (2009) discussed self-regulation and emotion (Carver \& Scheier, 2004) using behavioral systems theory. Behavioral systems theory is falsifiable because human and animal studies should link behaviors to specific neural networks that serve the system.

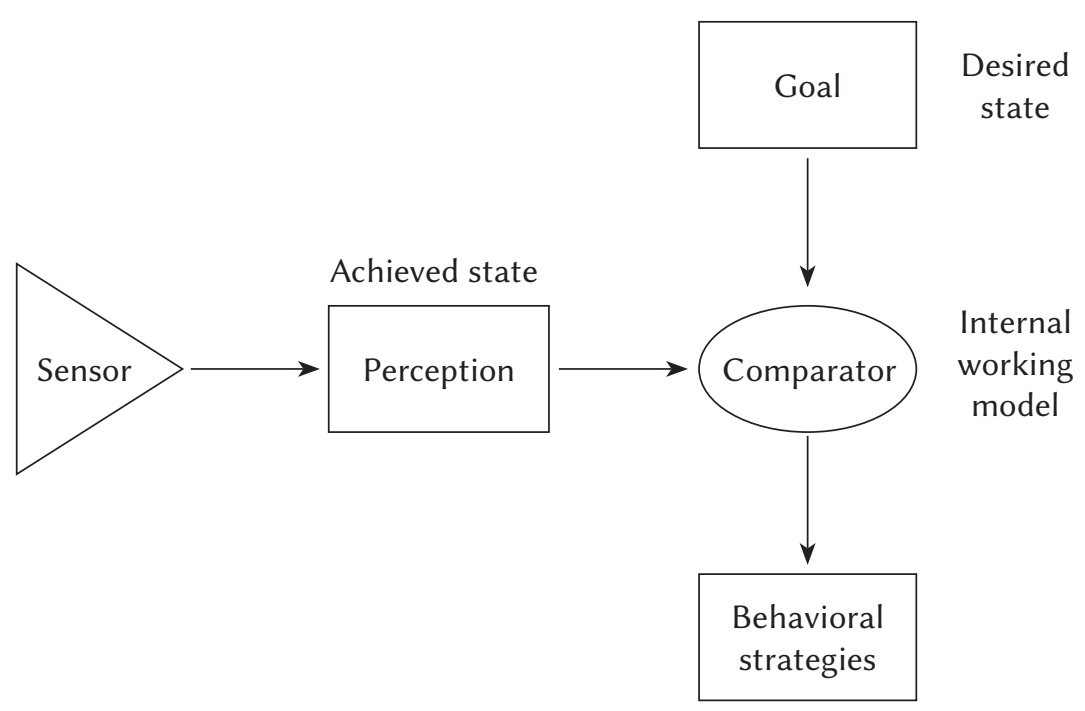

Figure 1. Diagram of a behavioral system. 
Bowlby correctly determined that behavioral systems could be used to unify the observations of psychoanalysts. However, his work only recognized the attachment system and did not consider what other social behavioral systems might contribute to normative behavior and psychopathology. Building on Gray's theory, a modern conceptualization recognizes that the behavioral activation system (BAS) mediates reward. There are four social behavioral systems that are subsystems of the BAS and that specifically mediate social reward (Leedom, 2014). In other words, there are four broad categories of adaptive social goals honed by evolution: 1) attachment/affiliation; 2) caregiving; 3) social power (dominance); and 4) sex. A specific neural network serves each of these adaptive goals (Goodson, 2005). Note that social bonds may form due to reward in each of these reward sub-systems (Depue \& Morrone-Strupinsky, 2005; Leedom, 2014), and the use of the term "attachment" for the affiliation system implies that bonds only form due to activity in that system. While it is true that mammalian social groups form for security or safety, bonds between individuals can form through sexual intercourse (Getz, Carter, \& Gavish, 1981), caregiving (as in maternal behavior) (Bell, 2001; Keverne \& Kendrick, 1992), and even dominance (Johnson, Leedom, \& Muhtadie, 2012; Swedell, Leedom, Saunders, \& Pines, 2013). Hence nomenclature has prevented the elaboration of a theory of social bonding as all social bonds are erroneously equated with "attachments" (Leedom, 2014; Noller \& Feeney, 2000). Carver and Scheier (2004) hypothesized that positive emotions serve as a feedback signal within behavioral systems and indicate that goals are being achieved; negative affect signals failure to achieve goals. Affects may also signal to the self and others activity in the neural circuits that serve behavioral systems (Bell \& Richard, 2000; Leedom, 2014). The regulation of motivations, behaviors and emotions associated with behavioral systems is termed self-regulation (Carver \& Scheier, 2004). Genetics dictate the inborn neural structures serving behavioral systems, but these structures develop under social environmental influences. Normative personality traits and personality disorders may be conceived of as arising through the activity of inborn yet developmentally acquired behavioral systems and through inborn yet developmentally acquired self-regulatory capacitiesThe behavioral system perspective unites the theories contained in the articles herein. Relational patterns are an integral part of normative and pathological personality (Soroko \& Cierpiałkowska, 2018), and these are dictated by the structure of an individual's social behavioral systems: attachment/affiliation, care-giving, dominance and sex. Genetically determined, developmentally acquired individual differences in the structure, interrelationships between, and regulation of, these systems and the BIS (anxiety system) determine personality organization. Individuals differ with re- spect to their social goals and motivations that reflect the degree to which affiliation, caregiving, dominance and sex are experienced as rewarding or important. Individuals also differ with respect to the behavioral strategies employed to achieve these goals. Learned behavioral strategies and self-regulation reflect parenting and culture such that an evaluation of strategies must take these into account (Gawda, 2018).

Those studying the motives of behavioral systems have long noted that implicit tests are the best means to assess these motives (Josephs, Sellers, Newman, \& Mehta, 2006; Schultheiss, 2008). McClelland (1975) then Winter (1992) pioneered the use of narratives to assess motives and internal working models. The Core Conflictual Relationship Theme method (CCRT) (Soroko \& Cierpiałkowska, 2018) and the Adult Attachment Inventory (Main, Hesse, \& Kaplan, 2005) also recognize the importance of narratives and the limitations of self-report in the assessment of behavioral systems. In addition to narratives, word finding tasks (Josephs et al., 2006) and the Implicit Association Test (IAT) have been used to implicitly assess social motives (Greenwald, Poehlman, Uhlmann, \& Banaji, 2009). Future research could compare these methods.

Integrated personality organization (IPO) indicates a person with adequate self-regulatory capacity, lack of overwhelming anxiety (neuroticism), affiliative tendencies and the ability to derive security from relationships. For a person with IPO, healthy relationships are maintained through empathy and compassion from a functional caregiving system and socially appropriate regulation of dominance (termed aggression by Soroko) and sex. Although aggression stems from the dominance behavioral system, in humans and other primates, social power may be achieved through "prosocial" means such as flattery, favors, sharing, etc. (Hawley, 2002). Hence, apparent caregiving strategies are part of the dominance behavioral system, and behavioral assessment of motives can be difficult. Individuals who employ a combination of aggressive and prosocial strategies are most successful at achieving power; however, the presence of aggressive strategies is a marker for poor mental health irrespective of prosocial strategies (Drath, 2017; Hawley, Shorey, \& Alderman, 2009). In IPO, the caregiving system exerts regulation over the dominance system (Harlow, 1973).

Mentalization, or the "process of social cognition that involves making inferences about one's own behavior and the behavior of other people on the basis of unobservable mental states" (Górska, 2015, p. 393), is a function of the comparator in each behavioral system. Zinczuk-Zielazna, Kleka, and Obrębska (2018) found that stress associated with the performance of public speaking impaired the cognitive task of verbal fluency. Cognitions are notoriously affected by anxiety. An optimal level of anxiety enhances cognition, but overwhelming anxiety impairs cognition (Hanoch \& Vitouch, 2004). Zinczuk-Zielazna, Kleka, and Obrębska 
(2018) and other papers in this volume point to the importance of self-regulation in personality functioning. In a non-clinical sample, stress facilitated verbal fluency, indicating that self-regulatory capacities normatively maintain optimal arousal in the presence of social demands. Failure of self-regulation may lead to distorted cognitions and impaired working models in individuals with personality disorders (Soroko \& Górska, 2018). Within behavioral systems, working models may be siloed such that there may be separate working models of attachment, caregiving, dominance and sex. Mentalization may differ according to which behavioral system or systems is activated at a given moment. IPO is characterized by self-regulation, realistic, balanced internal working models and sound reality testing.

"Empathy" takes on different characteristics depending upon whether the goal is power over or caring for another. Whereas theory of mind (Decety \& Meyer, 2008; Völlm et al., 2006) is important for power-related strategies, emotional empathy is a hindrance to power goals. Studies of mentalization might benefit from rating participants with respect to social motives. Individuals high in dominance would be expected to have normal to superior capacity for theory of mind but diminished capacity for emotional empathy. The combination of self-regulatory capacity, situational anxiety and social motives should explain most of the variance in empathy measures.

\section{BEHAVIORAL SYSTEMS AND PERSONALITY DISORDERS}

Borderline (BPD with BPO) and narcissistic personality disorder (NPD with NPO) and psychopathy are discussed in this volume. In interpreting findings it is important to recognize that these conditions are frequently comorbid (Hare \& Neumann, 2008), especially in forensic populations (Blackburn, Logan, Renwick, $\&$ Donnelly, 2005). NPD indicates an individual whose personality is organized (NPO) by the dominance behavioral system (Johnson et al., 2012) and who has deficiencies in the caregiving system. According to Soroko and Cierpiałkowska (2018), self-regulation may be moderately affected. Individuals with BPD and BPO suffer from deficient self-regulation, disturbed comparator function in the attachment/affiliation system, and deficient caregiving responses. If NPD/NPO is not comorbid, individuals with BPO should not possess excessive dominance motivation. However, due to deficits in self-regulation, dominance strategies in BPO may be primarily aggressive. NPO may be characterized by skillful use of prosocial (Soroko \& Cierpiałkowska, 2018) and aggressive dominance strategies (Hawley's bi-strategic dominance). This skillful use may be a source of success for those with NPO and reflect perceptions of the other as fulfilling rather than frustrating; excessive aggres- sion in BPO due to poor self-regulation of strategies would contribute to social rejection and representation of the other as frustrating (Drath, 2017; Hawley et al., 2009). Psychopathy is best conceptualized as a combination of all cluster B disorders (Hare \& Neumann, 2008). The degree of self-regulation deficits may determine subtypes of psychopathy (Blackburn \& Lee-Evans, 1985). Groth and Kleka (2018) state that "The tendency and ability of psychopathic individuals to engage in deception in interpersonal relationships, pathological lying, and manipulation is one of the distinctive features of their disorder." These strategies for dominance (Bursten, 1972) indicate that psychopathy is a disorder involving both excessive dominance motivation and aberrant dominance strategies. Assessment of psychopathy may be complicated by deception and manipulation (Groth \& Kleka, 2018). The Diagnostic and Statistical Manual of the American Psychiatric Association (DSM) (American Psychiatric Association, 2013) suggests that clinicians obtain history from collateral sources to circumvent deception. Another strategy would be to use narratives and implicit tests to augment collateral reports. Deficits in self-regulation may underlie patterns of faking good and faking bad in individuals with high levels of psychopathy as measured by the PPI.

\section{TINBERGEN'S FOUR QUESTIONS}

The four questions of ethology provide the basis for a complete explanation of behavior. These are 1) What is the cause of the behavior? (How is the behavior best described as part of a cybernetic system?); 2) How does the behavior develop? 3) What is the adaptive significance of the behavior?; and 4) What is the phylogeny of the behavior? Themes related to the four questions are found throughout this volume. Gawda (2018) discussed the cross-cultural prevalence of personality disorders in the context of evolutionary psychology and question 3. Differences in prevalence rates were found in individualistic verses collectivistic societies. The prevalence of antisocial personality disorder appears to be cross-culturally stable.

Recent human evolution should be considered when examining cross-cultural prevalence of personality disorders and Tinbergen's question 3. Anthropologists assert that hunter-gatherer societies are essentially egalitarian at least with respect to relations between men (Boehm, 1999). IPO would facilitate life in an egalitarian society. Parenting practices that favor IPO are those associated with monogamy and close mother infant bonds (Keller, Borke, Chaudhary, Lamm, \& Kleis, 2010). Contact comfort and responsive parenting facilitate self-regulation and the development of emotional empathy (Birmingham, Bub, \& Vaughn, 2017). About 10,000 years ago, humans developed agricultural technology and abandoned the hunter-gatherer lifestyle. 
This societal change made dominance advantageous (especially for men, who could increase their reproductive success due to the labors of others). Despotism, slavery and the maltreatment of women resulted from the agricultural revolution. In modern history, psychologists have directly observed that authoritarian leaders possess psychopathic personality traits (Lilienfeld et al., 2012; Winter, 1987) that have also been referred to as pathological narcissism (Lee, 2017). Furthermore, authoritarian leadership is made possible by personality traits that facilitate follower status (Pettigrew, 2017). Cross-cultural research examining follower status and IPO, NPO and BPO are necessary if psychology is to play a role in facilitating democracy, egalitarianism and human rights. Although modern society resulted from the power imbalances of the agricultural revolution, the determinants of IPO do not appear to have changed from what they were in human hunter-gatherer past. Psychology's task is to provide a unified theory that will aid in the education of parents and policy makers to improve mental health. Despite the apparent success of some with personality disorders, compassion and self-regulation characterize healthy personality.

\section{RefERENCES}

American Psychiatric Association (2013). Diagnostic and statistical manual of mental disorders 5. Washington, DC: American Psychiatric Association.

Bateson, P. P. G., Bateson, P. P. G., \& Klopfer, P. H. (1989). Perspectives in Ethology. Springer.

Bell, D. C. (2001). Evolution of parental caregiving. Personality and Social Psychology Review, 5, 216-229.

Bell, D. C., \& Richard, A. J. (2000). Caregiving: The forgotten element in attachment. Psychological Inquiry, 11, 69-83. doi: https://doi.org/10.1207/ S15327965PLI1102_01

Birmingham, R. S., Bub, K. L., \& Vaughn, B. E. (2017). Parenting in infancy and self-regulation in preschool: an investigation of the role of attachment history. Attachment \& Human Development, 19, 107-129. doi: https://doi.org/10.1080/14616734.2016.1259335

Blackburn, R., \& Lee-Evans, J. M. (1985). Reactions of primary and secondary psychopaths to anger-evoking situations. British Journal of Clinical Psychology, 24, 93-100. doi: https://doi. org/10.1111/j.2044-8260.1985.tb01319.x

Blackburn, R., Logan, C., Renwick, S. J. D., \& Donnelly, J. P. (2005). Higher-order dimensions of personality disorder: Hierarchical structure and relationships with the five-factor model, the interpersonal circle, and psychopathy. Journal of Personality Disorders, 19, 597-623. doi: https://doi. org/10.1521/pedi.2005.19.6.597

Boehm, C. (1999). Hierarchy in the Forest: The evolution of egalitarian behavior. Cambridge, MA: Harvard University Press.
Bowlby, J. (1980). By ethology out of psycho-analysis: An experiment in interbreeding. Animal Behaviour, 28, 649-656.

Bowlby, J. (1988). A secure base: Parent-child attachment and healthy human development. New York, NY: Basic Books.

Burkhardt, R. W. (2005). Patterns of Behavior: Konrad Lorenz, Niko Tinbergen, and the Founding of Ethology. Chicago, IL: University of Chicago Press.

Bursten, B. (1972). The manipulative personality. Archives of General Psychiatry, 26, 318-321. doi: https://doi.org/10.1001/archpsyc. 1972.01750220028005

Carver, C. S., Johnson, S. L., \& Joormann, J. (2009). Two-mode models of self-regulation as a tool for conceptualizing effects of the serotonin system in normal behavior and diverse disorders. Current Directions in Psychological Science, 18, 195-199.

Carver, C. S., \& Scheier, M. F. (2004). Self-regulation of action and affect. In R. F. Baumeister \& K. D. Vohs (Eds.), Handbook of Self-Regulation: Research, Theory, and Applications (pp. 13-39). New York, NY: Guilford Press.

Decety, J., \& Meyer, M. (2008). From emotion resonance to empathic understanding: A social developmental neuroscience account. Development and Psychopathology, 20, 1053-1080.

Depue, R. A., \& Morrone-Strupinsky, J. V. (2005). A neurobehavioral model of affiliative bonding: Implications for conceptualizing a human trait of affiliation. Behavioral and Brain Sciences, 28, 313-395. doi: https://doi.org/10.1017/S0140525X05000063

Drath, A.-F. (2017). Predictors of Adjustment to College (Education Doctorate). Bridgeport, CT: University of Bridgeport.

Gawda, B. (2018). Cross-cultural studies on the prevalence of personality disorders. Current Issues in Personality Psychology, 6, 318-329.

Getz, L. L., Carter, C. S., \& Gavish, L. (1981). The mating system of the prairie vole, Microtus ochrogaster: field and laboratory evidence for pair-bonding. Behavioral Ecology and Sociobiology, 8, 189-194.

Goodson, J. L. (2005). The vertebrate social behavior network: Evolutionary themes and variations. Hormones and Behavior, 48, 11-22. doi: https://doi. org/10.1016/j.yhbeh.2005.02.003

Górska, D. (2015). Mentalization, specific attachment, and relational satisfaction from the intrapsychic and interpersonal perspectives. Polish Psychological Bulletin, 46, 393-400.

Gray, J. A. (1990). Brain Systems that Mediate both Emotion and Cognition. Cognition \& Emotion, 4, 269288. doi: https://doi.org/10.1080/02699939008410799

Greenwald, A. G., Poehlman, T. A., Uhlmann, E. L., \& Banaji, M. R. (2009). Understanding and using the Implicit Association Test: III. Meta-analysis of predictive validity. Journal of Personality and Social Psychology, 97, 17-41. 
Groth, J., \& Kleka, P. (2018). Patterns of intentional faking in questionnaire-based study of psychopathy. Current Issues in Personality Psychology, 6, 305-317.

Hanoch, Y., \& Vitouch, O. (2004). When less is more: Information, emotional arousal and the ecological reframing of the Yerkes-Dodson law. Theory \& Psychology, 14, 427-452.

Hare, R. D., \& Neumann, C. S. (2008). Psychopathy as a clinical and empirical construct. Annual Review of Clinical Psychology, 4, 217-246. doi: https://doi. org/10.1146/annurev.clinpsy.3.022806.091452

Harlow, H. F. (1973). Learning to love. Oxford, England: Ballantine.

Hawley, P. H. (2002). Social dominance and prosocial and coercive strategies of resource control in preschoolers. International Journal of Behavioral Development, 26, 167-176. doi: https://doi. org/10.1080/01650250042000726

Hawley, P. H., Shorey, H. S., \& Alderman, P. M. (2009). Attachment correlates of resource-control strategies: Possible origins of social dominance and interpersonal power differentials. Journal of Social and Personal Relationships, 26, 1097-1118. doi: https://doi.org/10.1177/0265407509347939

Hinde, R. A. (1982). Ethology, its nature and relations with other sciences. New York, NY: Oxford University Press.

Johnson, S. L., Leedom, L. J., \& Muhtadie, L. (2012). The Dominance Behavioral System and Psychopathology: Evidence From Self-Report, Observational, and Biological Studies. Psychological Bulletin, 138, 692-743. doi: https://doi.org/10.1037/a0027503

Josephs, R. A., Sellers, J. G., Newman, M. L., \& Mehta, P. H. (2006). The mismatch effect: When testosterone and status are at odds. Journal of Personality and Social Psychology, 90, 999-1013. doi: https://doi.org/10.1037/0022-3514.90.6.999

Keller, H., Borke, J., Chaudhary, N., Lamm, B., \& Kleis, A. (2010). Continuity in parenting strategies: A crosscultural comparison. Journal of Cross-Cultural Psychology, 41, 391-409.

Keverne, E. B., \& Kendrick, K. M. (1992). Oxytocin Facilitation of Maternal Behavior in Sheep. Annals of the New York Academy of Sciences, 652, 83-101.

Lee, B. X. (2017). The dangerous case of Donald Trump: 27 psychiatrists and mental health experts assess a president. New York, NY: Thomas Dunne Books.

Leedom, L. J. (2014). Human Social Behavioral Systems: Ethological framework for a unified theory. Human Ethology Bulletin, 29, 39-65.

Lilienfeld, S. O., Waldman, I. D., Landfield, K., Watts, A. L., Rubenzer, S., \& Faschingbauer, T. R. (2012). Fearless Dominance and the U.S. Presidency: Implications of Psychopathic Personality Traits for Successful and Unsuccessful Political Leadership. Journal of Personality and Social Psychology, 103, 489-505. doi: https://doi.org/10.1037/a0029392
Main, M., Hesse, E., \& Kaplan, N. (2005). Predictability of Attachment Behavior and Representational Processes at 1, 6, and 19 Years of Age: The Berkeley Longitudinal Study. In K. E. Grossmann, K. Grossmann, \& E. Waters (Eds.), Attachment from infancy to adulthood: The major longitudinal studies (pp. 245-304). New York, NY: Guilford Publications.

McClelland, D. C. (1975). Power: The inner experience. Oxford, England: Irvington.

Noller, P., \& Feeney, J. A. (2000). Parent-child emotional bonds: Loving or caring? Psychological Inquiry, 11, 91-94.

Pettigrew, T. F. (2017). Social psychological perspectives on Trump supporters. Journal of Social and Political Psychology, 5, 107-116.

Schultheiss, O. C. (2008). Implicit motives. In O. P. John, R. W. Robins, \& L. A. Pervin (Eds.), Handbook of personality psychology: Theory and research (3rd ed., pp. 603-633). New York, NY: Guilford Press.

Soroko, E., \& Cierpiałkowska, L. (2018). Levels of personality organization and internal relational patterns. Current Issues in Personality Psychology, 6, 292-304.

Soroko, E., \& Górska, D. (2018). Beyond descriptions. Selected aspects of science and practice in clinical psychology. Editorial. Current Issues in Personality Psychology, 6, 261-265.

Swedell, L., Leedom, L., Saunders, J., \& Pines, M. (2013). Sexual conflict in a polygynous primate: costs and benefits of a male-imposed mating system. Behavioral Ecology and Sociobiology, 68, 263273. doi: https://doi.org/10.1007/s00265-013-1641-3 Tinbergen, N. (1963). On aims and methods of ethology. Zeitschrift Für Tierpsychologie, 20, 410-433.

Völlm, B. A., Taylor, A. N. W., Richardson, P., Corcoran, R., Stirling, J., McKie, S., Deakin, J. F., \& Elliott, R. (2006). Neuronal correlates of theory of mind and empathy: A functional magnetic resonance imaging study in a nonverbal task. Neurolmage, 29, 90-98. doi: https://doi.org/doi: DOI: 10.1016/j.neuroimage. 2005.07.022

Winter, D. G. (1987). Leader appeal, leader performance, and the motive profiles of leaders and followers: A study of American presidents and elections. Journal of Personality and Social Psychology, 52, 196-202.

Winter, D. G. (1992). Power motivation revisited. In C. P. Smith, J. W. Atkinson, D. C. McClelland, \& J. Veroff (Eds.), Motivation and personality: Handbook of thematic content analysis (pp. 301310). New York, NY: Cambridge University Press.

Zinczuk-Zielazna, J., Kleka, P., \& Obrębska, M. (2018). Verbal fluency and emotional expression in young women differing in their styles of coping with threatening stimuli. Current Issues in Personality Psychology, 6, 330-342. 